\title{
The impact of diabetes mellitus on survival following resection and adjuvant chemotherapy for pancreatic cancer
}

Jörg Kleeff ${ }^{\star}, 1,2,5$, Eithne Costello ${ }^{1,2,5}$, Richard Jackson ${ }^{1,2}$, Chris Halloran ${ }^{1,2}$, William Greenhalf ${ }^{1,2}$, Paula Ghaneh ${ }^{1,2}$, Richard F Lamb ${ }^{1,2}$, Markus M Lerch ${ }^{3}$, Julia Mayerle ${ }^{3}$, Daniel Palmer ${ }^{1,2}$, Trevor Cox ${ }^{1,2}$, Charlotte L Rawcliffe ${ }^{1,2}$, Oliver Strobel ${ }^{4}$, Markus W Büchler ${ }^{4}$ and John P Neoptolemos ${ }^{1,2}$ for the European Study Group for Pancreatic Cancer

${ }^{1}$ Liverpool Cancer Research UK Cancer Trials Unit, Liverpool Cancer Research UK Centre, University of Liverpool, Liverpool, UK; ${ }^{2}$ NIHR Pancreas Biomedical Research Unit, University of Liverpool, Liverpool L69 $3 G A$, UK; ${ }^{3}$ Department of Medicine A, ErnstMoritz-Arndt-University Greifswald, Greifswald, Germany and ${ }^{4}$ Department of Surgery, University of Heidelberg, Heidelberg, Germany

Background: Diabetes mellitus is frequently observed in pancreatic cancer patients and is both a risk factor and an early manifestation of the disease.

Methods: We analysed the prognostic impact of diabetes on the outcome of pancreatic cancer following resection and adjuvant chemotherapy using individual patient data from three European Study Group for Pancreatic Cancer randomised controlled trials. Analyses were carried out to assess the association between clinical characteristics and the presence of preoperative diabetes, as well as the effect of diabetic status on overall survival.

Results: In total, 1105 patients were included in the analysis, of whom 257 (23\%) had confirmed diabetes and 848 (77\%) did not. Median (95\% confidence interval (CI)) unadjusted overall survival in non-diabetic patients was 22.3 (20.8-24.1) months compared with 18.8 (16.9-22.1) months for diabetic patients $(P=0.24)$. Diabetic patients were older, had increased weight and more co-morbidities. Following adjustment, multivariable analysis demonstrated that diabetic patients had an increased risk of death (hazard ratio: $1.19(95 \% \mathrm{Cl} 1.01,1.40), P=0.034)$. Maximum tumour size of diabetic patients was larger at randomisation (33.6 vs $29.7 \mathrm{~mm}, P=0.026)$.

Conclusions: Diabetes mellitus was associated with increased tumour size and reduced survival following pancreatic cancer resection and adjuvant chemotherapy.

Pancreatic cancer is currently the fourth most common cause of cancer-related mortality in developed countries (Siegel et al, 2015) and is predicted to be the second leading cause within the next decade (Rahib et al, 2014). Most patients are diagnosed at an advanced stage with distant metastasis and/or locally advanced unresectable tumours (Hidalgo et al, 2015). Together with limited and often ineffective treatment options, this results in an overall low 5 -year survival rate of $<7 \%$. Surgery, the only chance for cure, can be offered to only $15-20 \%$ of patients resulting in $\sim 20 \%$ 5-year survival rates (Kleeff et al, 2016).

Risk factors that have been identified for pancreatic cancer include tobacco smoking, diabetes mellitus and others

\footnotetext{
*Correspondence: Professor J Kleeff; E-mail: Kleeff@liverpool.ac.uk

${ }^{5}$ These authors contributed equally to this work.
}

Received 29 April 2016; revised 23 July 2016; accepted 8 August 2016; published online 1 September 2016

(c) 2016 Cancer Research UK. All rights reserved 0007 - 0920/16 
(Bosetti et al, 2012; Kleeff et al, 2016). Several studies have established that diabetes mellitus has a higher prevalence in patients with pancreatic cancer than other cancers or control subjects especially in patients with a more recent diagnosis (Chari et al, 2008; Pannala et al, 2008; Aggarwal et al, 2013). Systematic reviews and meta-analyses have confirmed that diabetes is a risk factor for pancreatic cancer with risk ratios of around 1.8-2.1 (Huxley et al, 2005; Ansary-Moghaddam et al, 2006; Stevens et al, 2007; Ben et al, 2011). The risk is higher with recent onset diabetes (Calle et al, 1998; Huxley et al, 2005; Ben et al, 2011), possibly as an early manifestation of pancreatic cancer. In contrast to an earlier report (Gullo et al, 1994), long-standing diabetes mellitus ( $>5$ years) has also been shown to have an increased risk ratio of pancreatic cancer of 1.5-2.0 (Everhart and Wright, 1995; Huxley et al, 2005; Li et al, 2011). There is still an excess risk of pancreatic cancer even with a long-standing diagnosis of diabetes of 20 years or more, but at a lower level with an odds ratio (OR) of 1.3 (Bosetti et al, 2014). There is some evidence that diabetes mellitus may resolve after pancreatic cancer resection in a proportion of new onset cases, whereas it remains unchanged in patients with longstanding diabetes (Permert et al, 1993; Pannala et al, 2008), which appears to be specific for pancreatic cancer, as resection for chronic pancreatitis does not improve pre-existing diabetes (Litwin et al, 2008). Although diabetes mellitus increases the risk of pancreatic cancer, there is also evidence that pancreatic cancer itself induces diabetes (type 3c). Potential mechanisms include the release of adrenomedullin, a potential mediator of beta cell dysfunction (Aggarwal et al, 2012) or by beta cell apoptosis induced by pancreatic stellate cells (Kikuta et al, 2013). Thus, diabetes is both causal and consequential to pancreatic cancer, the latter offering a window for screening, early tumour detection and therapy (Jenkinson et al, 2015).

The survival of diabetic cancer patients compared with normoglycemic individuals across all cancer types seems to be less with risk ratios of around 1.4 (van de Poll-Franse et al, 2007; Barone et al, 2008), but not for pancreatic cancer, possibly because of the limited cohort size (Park et al, 2006). Analysis of diabetes as covariate on survival outcome in advanced pancreatic is difficult due to the large number of variables and the very short survival. Preoperative diabetes found in 275 (56.3\%) of 488 patients with pancreatic cancer that had resection also did not influence survival although tumour size was significantly larger $($ mean $=36 \mathrm{~mm}$ ) compared with the non-diabetics (mean $=33 \mathrm{~mm}$ ) (Hart et al, 2014). In another study, 93 (45.4\%) of 209 patients with pancreatic cancer and preoperative diabetes had a median survival of 15 months, which was less compared with 17 months in nondiabetics with a hazard ratio (HR) of 1.55 (Chu et al, 2010). The risk of survival was even less in new onset diabetics $(<2$ years duration) compared with the long-standing diabetics with a HR of 1.75 (Chu et al, 2010). Diabetics also had a larger tumour size $($ mean $=38 \mathrm{~mm})$ compared with non-diabetics $($ mean $=32 \mathrm{~mm})$.

Thus, the prognostic effect of diabetes mellitus in patients with pancreatic cancer is uncertain. The purpose of this study was to analyse the prognostic effect of clinically revealed diabetes on longterm survival in pancreatic cancer patients following resection and adjuvant chemotherapy from three randomised controlled trials of the European Study Group for Pancreatic Cancer (ESPAC) trials, namely ESPAC-1Plus, ESPAC-1 and ESPAC-3 (Neoptolemos et al, 2001, 2004, 2009, 2010).

\section{MATERIALS AND METHODS}

Patients. Patients with pancreatic ductal adenocarcinoma were identified from the ESPAC-1Plus, ESPAC-1 and ESPAC-3 trials (Neoptolemos et al, 2001, 2004, 2009, 2010). These were open label, international, randomised phase III studies. In order to improve homogeneity patients randomised to receive chemotherapy only were selected for this analysis. Patients were excluded if they had been randomised to either chemoradiation or to observation. There were 541 patients randomised together in ESPAC-1Plus and ESPAC-1 of whom 164 patients were randomised to chemotherapy alone. There were 25 (15\%) of these 164 patients with diabetes. There were 941 patients with ductal adenocarcinoma randomised in ESPAC-3 to either of two adjuvant chemotherapy regimens. There were 232 (25\%) of these 941 patients with diabetes. The diabetes mellitus status was prospectively obtained by the principal investigator at each of the referring sites according to the best available clinical evidence and guidelines at that time and site, and categorised as no diabetes, insulin-dependent or non-insulin-dependent diabetes. Glucose tolerance testing or fasting glucose measurements were not routinely carried out, and data regarding duration of diabetes were not recorded (Neoptolemos et al, 2001, 2004, 2009, 2010).

Statistical analysis. Clinical characteristics were compared across diabetic groups using two-sided Mann-Whitney Ustatistics for continuous characteristics and the $\chi^{2}$-test for categorical variables. Multivariable regression using logistic regression was used to assess the relationship between clinical characteristics and diabetic status. The primary outcome of interest was overall survival measured as the time from surgery until death by any cause. Survival estimates are calculated using the method of Kaplan and Meier (Kaplan and Meier, 1958) and compared across biological groups using Log-rank tests (Peto and Peto, 1972). Median follow-up is calculated using the reverse Kaplan-Meier approach (Schemper and Smith, 1996). Multivariable analyses are carried out using Cox proportional hazards models (Cox, 1972) and are constructed using forward selection based on Akaike's Information Criterion. The effects for trial and country are both included as stratification factors. Only covariated with a univariate significance of $P<0.25$ are considered for selection in the multivariable model. Assessment of maximum tumour size (MTS) carried out using a $\log (\mathrm{x}+1)$ transformation on continuous covariate. Proportional hazards assumptions were evaluated via assessment of Schoenfelds residuals (Schoenfeld, 1982). Further sensitivity analyses are carried out using a landmark method, excluding patients who died within 30,60 and 90 days of randomisation. All analyses were carried out using $\mathrm{R}$ ( $\mathrm{v}$ 3.2.1) (R-Development-Core-Team, 2011) on an intention to treat basis, retaining patients in their randomised treatment groups and including protocol violators and ineligible patients. A two-sided significance of $P<0.05$ was used throughout.

\section{RESULTS}

Clinical and pathological variables. A total of 1105 patients were included in the analysis, 164 (15\%) patients from the ESPAC-1 studies and 941 (85\%) patients from the ESPAC-3 study. There were $25(15 \%)$ and $232(25 \%)$ diabetics, respectively, from these studies. Together there were 257 (23\%) patients with clinically revealed diabetes mellitus and $848(77 \%)$ who were non-diabetic at the point of randomisation. Patient characteristics at baseline and univariate analyses are presented to identify patient characteristics associated with diabetes (Table 1). Patients with diabetes were significantly older with a median (interquartile range) age of $65(57-71)$ vs 63 (56-69) years for non-diabetics $(P=0.04)$, and had an increased median (interquartile range) weight at presentation of $72(62,80)$ vs $66(58,75) \mathrm{kg}$ for non-diabetics $(P<0.001)$. Diabetic patients were also more likely to have concurrent medical conditions other than diabetes (64\% vs 42\%; P<0.001). About 146 of 257 (57\%) diabetic patients completed all six cycles of adjuvant therapy, which was not significantly different from the 458 of 848 (54\%) non-diabetic 


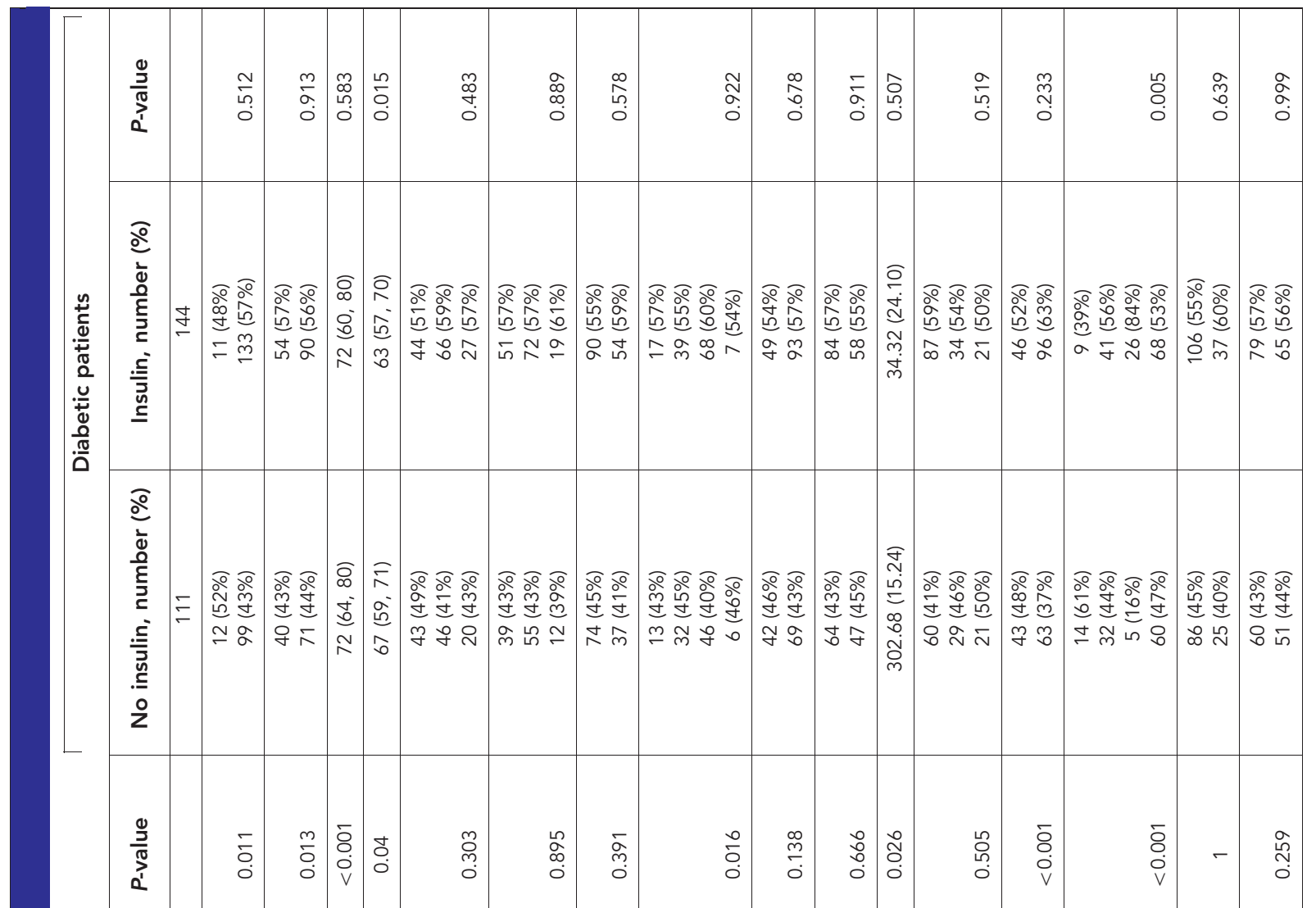

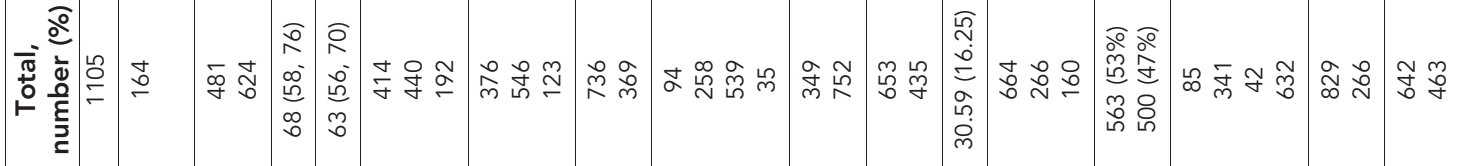

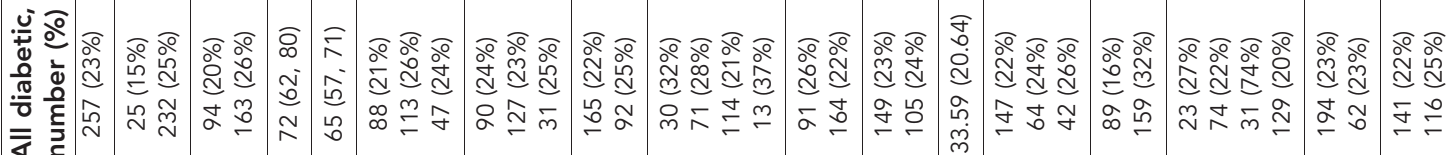

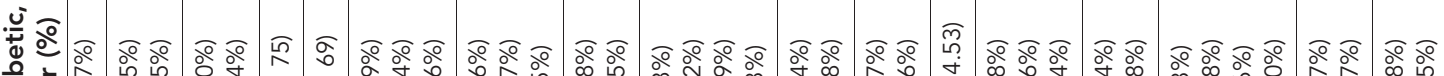

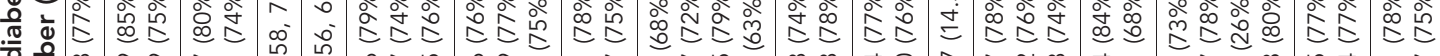
至

\begin{tabular}{|c|c|c|c|c|c|c|c|c|c|c|c|c|c|c|c|c|c|}
\hline 㐫 & $\overline{\bar{\alpha}}$ & 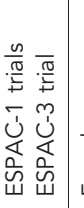 & 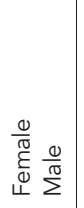 & 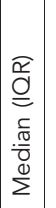 & 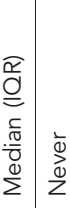 & 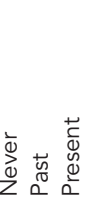 & $0-N$ & 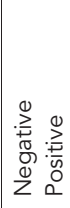 & $-\sim m \sigma$ & 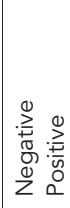 & $2 \stackrel{\infty}{=}$ & 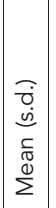 & 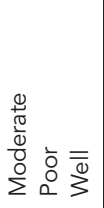 & $\dot{2} \stackrel{\infty}{x}$ & 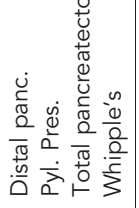 & 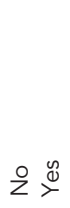 & 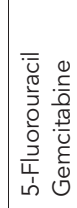 \\
\hline 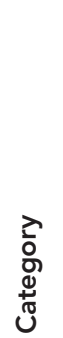 & 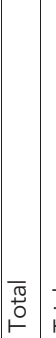 & 说 & 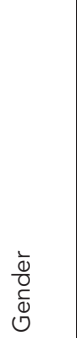 & 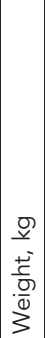 & 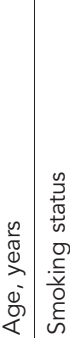 & 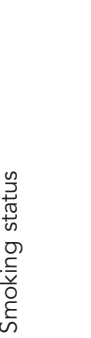 & 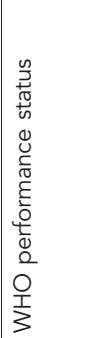 & 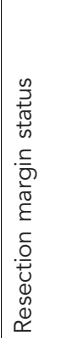 & 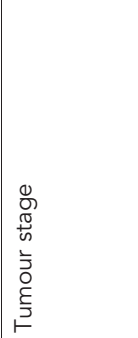 & 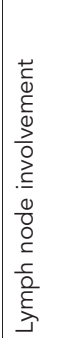 & 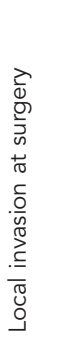 & 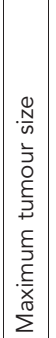 & 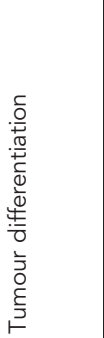 & 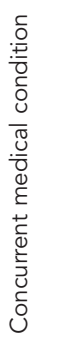 & $\begin{array}{l}\frac{.0}{0} \\
\frac{0}{0} \\
\frac{0}{0} \\
0 \\
0\end{array}$ & 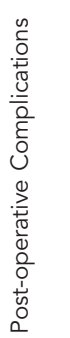 & 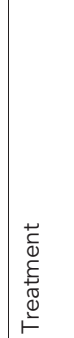 \\
\hline
\end{tabular}




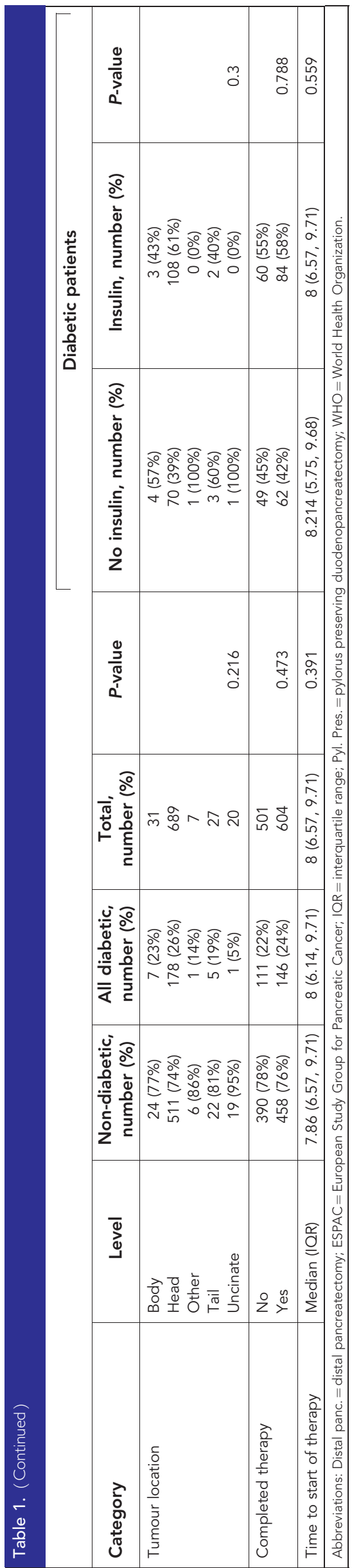

patients $(P=0.47)$. The mean (s.d.) MTS was 33.59 (20.64) $\mathrm{mm}$ in diabetic patients and $29.67(14.53) \mathrm{mm}$ in non-diabetic patients with significantly larger tumours in diabetic patients $(P=0.026$, MTS compared on the log scale). Diabetic patients had proportionally larger resections in the form of total pancreatectomy (12\%) compared with non-diabetics $(1 \% ; P<0.001)$ although the distribution of tumour location was not significantly different between diabetic and non-diabetic patients $(P=0.216)$. There were no significant preoperative or post-operative differences between insulin-dependent and non-insulin-dependent patients. Multivariable analysis identified increased age and increased weight as clinical characteristics independently associated with preoperative diabetes (Table 2). Further, increased MTS but also a lower proportion of positive lymph nodes, were independently associated with preoperative diabetes.

Overall survival. Eight hundred and sixty two patients (78\%) died during the course of both trial sets. The median (95\% confidence interval (CI)) overall survival was $21.4(20.2,23.4)$ months. The median (95\% CI) overall survival for non-diabetics was 22.3 (20.824.1) months compared with 18.8 (16.9-22.1) months for diabetic patients. Analysis of the overall survival by diabetic status obtained $X^{2} \mathrm{LR}_{(1 \mathrm{DF})}=1.39 \quad(P=0.238)$. Multivariable model analysis for overall survival identified World Health Organization performance status and smoking status as independent prognostic clinical indicators and resection margin status, tumour differentiation and lymph node involvement as independent prognostic pathological indicators (Table 3). Following adjustment of other terms, diabetic status was significantly associated with survival, with diabetic patients having an increased risk of death (HR: 1.19 (95\% CI: 1.01, $1.40), P=0.034)$. The fitted effect of diabetic status is given in Figure 1. Assessment of Schoenfeld residuals did not identify any prognostic factors, which may be associated with non-proportional hazards.

Of the 257 patients who were diabetic, insulin status was missing in two patients. One hundred and forty four (56\%) of these 255 patients were insulin dependent and the remainder $(n=111)$ were non-insulin dependent received either oral antidiabetics or were controlled by diet alone. At least 13 patients were receiving oral antidiabetic therapy (seven taking metformin), but specific information was not available for the remaining 98 non-insulindependent diabetics. The median (95\% CI) overall survival estimates was $18.0(16.5,21.1)$ months for patients who used insulin and $20.5(16.0,26.6)$ months for patients who did not use insulin. The unadjusted overall survival by diabetic status was not significant $\left(X_{\mathrm{LR}(1 \mathrm{DF})}^{2}=0.03, P=0.857\right)$. The unadjusted overall survival for diabetics in those using insulin $v s$ metformin $v s$ other oral diabetic medication was not significant $\left(X_{\mathrm{LR}(2 \mathrm{DF})}^{2}=0.80\right.$, $P=0.371)$. The median $(95 \% \mathrm{CI})$ overall survival estimates was $18.0(16.5,21.1)$ months for patients who used insulin $(n=144)$ and $22.2(20.7,23.9)$ months for patients who were not diabetic or who were non-insulin dependent $(n=959) \quad\left(X_{\mathrm{LR}(1 \mathrm{DF})}^{2}=0.4\right.$, $P=0.527)$.

In insulin-dependent diabetic patients, the median (95\% CI) overall survival estimates with a maximum tumour diameter $>30 \mathrm{~mm}$ was 17.0 (15.2-22.7) months compared with 18.5 (15.9-26.1) months for patients with a maximum tumour diameter $\leqslant 30 \mathrm{~mm}(\mathrm{HR}(95 \% \mathrm{CI})=0.96(0.65,1.4) ; P=0.823)$. In noninsulin diabetic-dependent patients, the median (95\% CI) overall survival estimates with a maximum tumour diameter $>30 \mathrm{~mm}$ was 14.6 (9.51-21.9) months compared with 32.0 (22.11-41.4) months for patients with a maximum tumour diameter $\leqslant 30 \mathrm{~mm}$ $(\mathrm{HR}(95 \% \mathrm{CI})=1.99(1.30,3.03) ; P<0.001)$. The overall survival difference was significant $\left(X_{\mathrm{LR}(3 \mathrm{DF})}^{2}=10.37, P=0.016\right)$ (Figure 2).

A multivariable analysis was carried out on factors independently associated with overall survival specifically in the 257 diabetic patients. Due to the interaction between insulin status 
and MTS, we included the latter as a nested effect within insulin status, allowing for separate HRs for insulin-dependent and nondependent groups. This showed that lymph node metastasis remained an independent prognostic factor (Table 4). There was also a significant effect of MTS for non-insulin-dependent patients but not for patients who were insulin dependent. Landmark

Table 2. Multivariable logistic regression on baseline clinical and pathological variable independently associated with preoperative diabetes

\begin{tabular}{|l|c|c|c|}
\hline Term & Est (s.e.) & Odds ratio (95\% confidence interval) & $P$-value \\
\hline Intercept & $-3.49(0.544)$ & & $<0.001$ \\
\hline Maximum tumour size ${ }^{\mathrm{a}}$ & $0.21(0.103)$ & $1.23(1.006,1.505)$ & 0.044 \\
\hline Weight & $0.03(0.006)$ & $1.03(1.016,1.039)$ & $<0.001$ \\
\hline Age & $0.02(0.009)$ & $1.02(1.005,1.042)$ & 0.011 \\
\hline Lymph node status & $-0.32(0.155)$ & $0.73(0.538,0.986)$ & 0.04 \\
\hline $\begin{array}{l}\text { Abbreviation: Est }=\text { estimated. } \\
\text { a Tumour size is included in the model using a } \log (\mathrm{x}+1) \text { transformation. }\end{array}$ \\
\hline
\end{tabular}

\section{Table 3. Cox proportional hazards model of factors independently associated with overall survival}

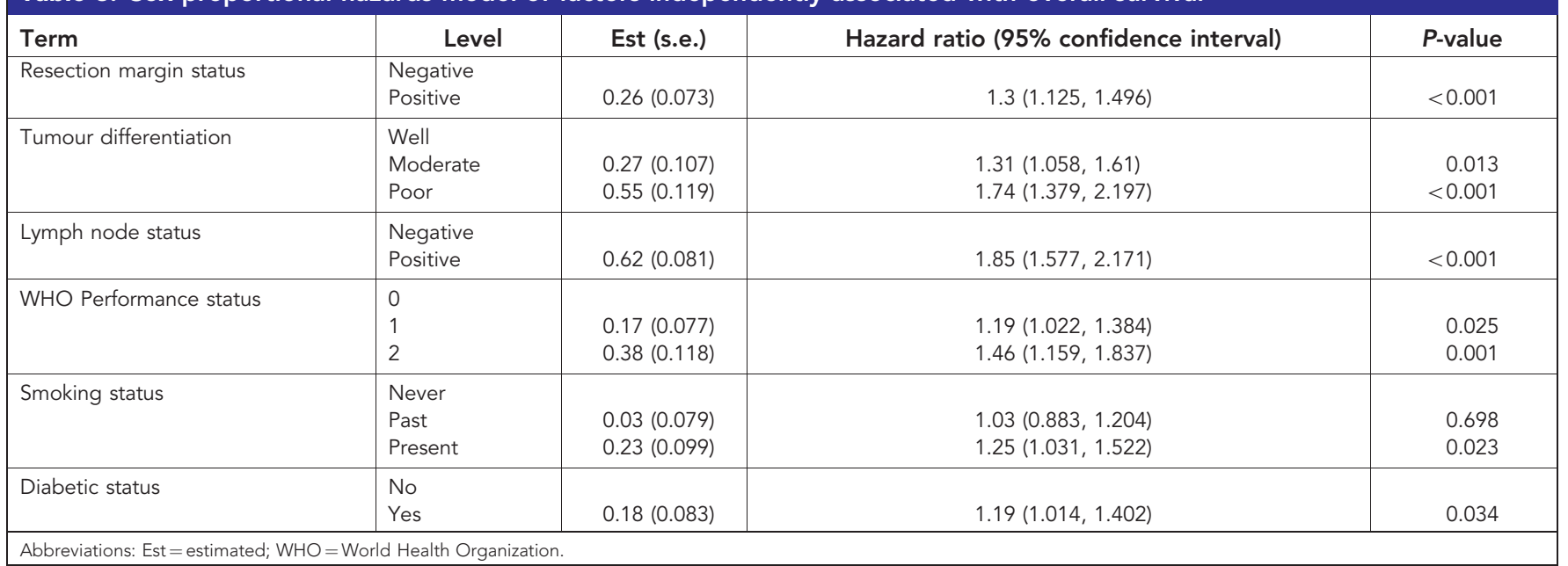

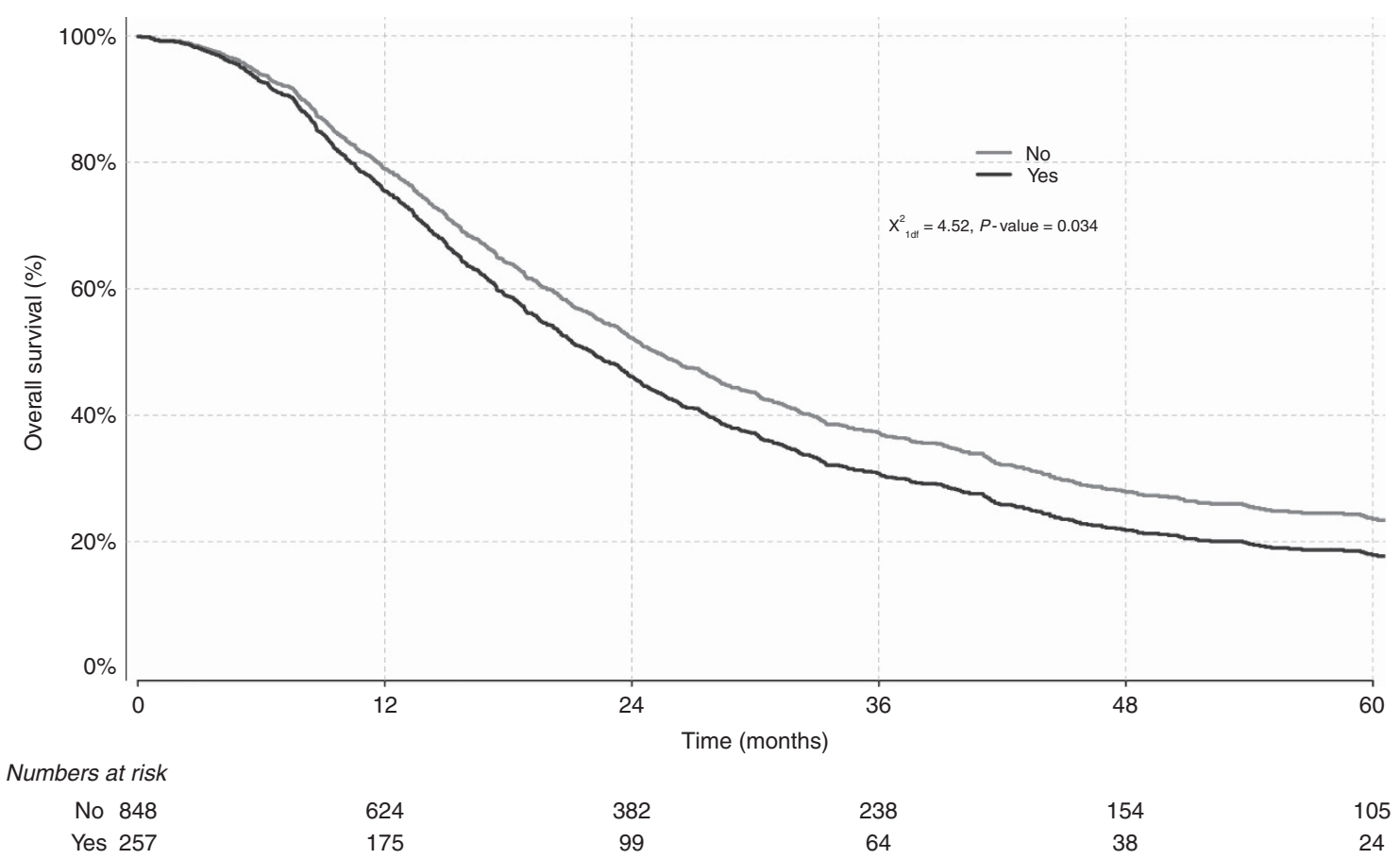

Figure 1. Fitted effect of diabetic status on overall survival in 1105 pancreatic cancer patients following resection and adjuvant chemotherapy. Yes = diabetic patients; No=non-diabetic patients. 


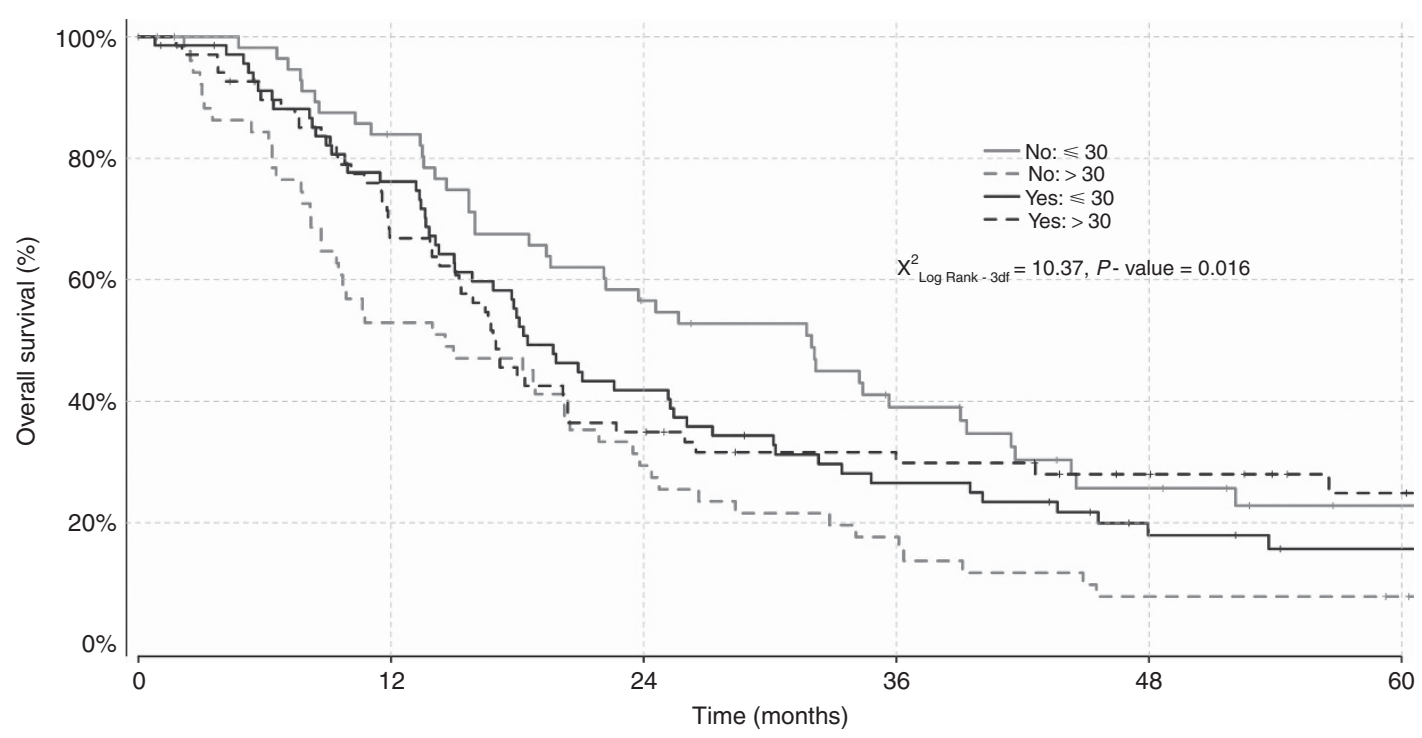

Numbers at risk

$\begin{array}{ccccccc}\text { No: } \leqslant 30 & 57 & 46 & 30 & 19 & 11 & 6 \\ \text { No: }>30 & 53 & 27 & 15 & 9 & 4 & 3 \\ \text { Yes: } \leqslant 30 & 70 & 51 & 28 & 17 & 9 & 6 \\ \text { Yes: }>30 & 68 & 44 & 23 & 17 & 13 & 8\end{array}$

Figure 2. Overall survival analysis in diabetic patients stratified according to whether patients were insulin dependent (Yes) vs non-insulin dependent (No), and maximum tumour diameter $>30 \mathrm{~mm}$ vs $\leqslant 30 \mathrm{~mm}$.

Table 4. Cox proportional hazards regression of factors independently associated with overall survival in diabetic patients

\begin{tabular}{|l|l|c|c|l|}
\hline Term & Level & Est (s.e.) & Hazard ratio (95\% confidence interval) & $P$-value \\
\hline Lymph node status & $\begin{array}{l}\text { Negative } \\
\text { Positive }\end{array}$ & $0.86(0.165)$ & $2.37(1.714,3.272)$ & $<0.001$ \\
\hline Insulin dependent & $\begin{array}{l}\text { No } \\
\text { Yes }\end{array}$ & $1.86(0.818)$ & $6.45(1.298,32.014)$ & 0.023 \\
\hline Non-insulin dependent & Maximum tumour size ${ }^{a}$ & $0.51(0.212)$ & $1.67(1.103,2.533)$ & 0.015 \\
\hline Insulin dependent & Maximum tumour size ${ }^{a}$ & $-0.06(0.097)$ & $0.94(0.78,1.142)$ & 0.553 \\
\hline $\begin{array}{l}\text { Abbreviation: Est }=\text { estimated. } \\
\text { a } \text { Maximum tumour size is included in the model using a log }(\mathrm{x}+1) \text { transformation. }\end{array}$ \\
\hline
\end{tabular}

analyses, removing patients who died within the first 30, 60 and 90 days, respectively, showed that the magnitude and direction of all treatment effects remained consistent showing that the effects reported are not overly effected by early deaths. Details are included in Supplementary Table 1. Further to this, assessment of Schoenfeld residuals did not identify any prognostic factors, which may be associated with non-proportional hazards.

\section{DISCUSSION}

The present study shows that diabetes mellitus is associated with increased tumour size and a small but significant increased overall risk of death with a HR of 1.19. There was a significant effect of MTS on survival for non-insulin-dependent but not for insulindependent diabetic patients. Two specific smaller studies also showed increased tumour size with diabetes with only one of these found a worse prognosis for diabetic patients following tumour resection (Chu et al, 2010; Hart et al, 2014). A meta-analysis of retrospective studies demonstrated worse prognosis in diabetic patients following resection with a HR of 1.32 (Walter et al, 2014).

Taken together, there is now solid evidence that the diabetic state at the time of resection influences outcome. There are several concepts on how diabetes mellitus might impact on prognosis of pancreatic cancer patients. Patients with long-standing type II diabetes exhibit insulin resistance and hypersecretion of insulin (Fisher et al, 1996; Li, 2012). In addition, elevated insulin levels result in increased bioavailability of IGFs and pancreatic cancer cells highly express high-affinity insulin and IGF receptors (Li, 2012). Insulin has been shown to act as a mitogen for pancreatic cancer cells (Fisher et al, 1996; Ding et al, 2000), and IGF-1 besides its mitogenic effects, induces angiogenesis and increases invasion and blocks apoptosis of pancreatic cancer cells, thereby promoting tumour growth (Li, 2012). In line with this hypothesis, this and two other mentioned studies (Chu et al, 2010; Hart et al, 2014) have shown that diabetic patients have larger tumours at the time of resection. The present study has also demonstrated that the effects of diabetes on outcome were independent from tumour size, suggesting that other mechanisms are responsible for the worse prognosis of diabetic patients. It is conceivable that in the adjuvant setting, hyperinsulinemia supports growth of occult pancreatic cancer cells, resulting in worsened prognosis. This might further be augmented by related obesity, leading to enhanced oxidative stress and inflammatory responses ( $\mathrm{Li}, 2012)$. Indeed, the median weight of diabetic patients was significantly higher than of non-diabetic patients in the present analysis. 
The association between diabetes and tumour size has been substantiated from three large trials. Here, we show in addition, that in the group of diabetic patients, tumour size was an important prognostic indicator in non-insulin-dependent, but not in insulin-dependent patients. This suggests that in non-insulindependent diabetes mellitus, tumour size has a predominant effect on prognosis, whereas insulin-dependent diabetes mellitus has a stronger, likely systemic effect on survival. There is evidence that therapies that increase insulin levels such as exogenous insulin or sulfonylurea could increase cancer risk. Therapies that decrease insulin levels by decreasing insulin resistance such as metformin, which also inhibits mTOR activity (Gong et al, 2014 ), would decrease the risk. Long duration ( $\geqslant 15$ years) of oral antidiabetics is associated with a decreased pancreatic cancer risk (OR 0.31), whereas insulin use ( $<5$ years) is associated with increased cancer risk (OR 5.6) (Bosetti et al, 2014). A casecontrol study has shown that diabetic patients on metformin had a significantly reduced risk of pancreatic cancer compared with patients not on metformin. In contrast, patients on insulin or insulin secretagogues had a significantly higher risk (Li et al, 2009), while a meta-analysis showed a reduced pancreatic cancer risk for patients on metformin but not sulfonylurea (Soranna et al, 2012). Another recent meta-analysis could not verify these associations between metformin or insulin and pancreatic cancer risk (Singh et al, 2013).

A previous study has shown that the effect on survival was especially pronounced for recent onset diabetes (Chu et al, 2010). Tumours that induce diabetes might constitute a more aggressive subtype. Alternatively, symptoms of diabetes may mask symptoms of a developing tumour and contribute to delayed diagnosis. Our data on this aspect are conflicting, in as much as tumours of diabetic patients were significantly larger, but had significantly less lymph node involvement and did not display differences in tumour differentiation. Furthermore, diabetic patients might have been treated less aggressively than nondiabetic patients, as it has been shown for other tumour entities (van de Poll-Franse et al, 2007), although there was no difference in surgery and adjuvant therapy (including completion of therapy) in our series. On the other hand, it is also conceivable that cancer-induced diabetes results in earlier diagnosis, and thus in potentially better outcome. It could be speculated that all of these effects might have a role and that our data reflect the sum of these effects.

This study relied on clinical data collected in prospectively randomised controlled trials of patients with histological proven ductal adenocarcinoma involving a total of 1105 patients of whom 257 (23\%) were diabetic (Neoptolemos et al, 2001, 2004, 2009, 2010). Diabetes mellitus status was determined by the principal investigator at each of the referring sites according to the best available clinical evidence and guidelines at that time and site. This is a limitation of the present study, as no clear definition or test was utilised. Diagnosis reflected actual clinical care at the different sites and under-diagnosis is a likely issue, as routine use of specific tests (e.g. glucose tolerance test) was not mandatory within the ESPAC study protocols. Thus, it is possible that some of the patients were actually diabetic, but had not been formally assessed prior to therapy.

In conclusion, diabetic patients who undergo resection for pancreatic cancer and adjuvant therapy present with larger tumours and have a small but significantly higher risk of death than non-diabetic patients. There seem to be important differences in patients with pancreatic cancer between those with insulin- and non-insulin-dependent diabetes mellitus and from previous studies between those with new onset and established diabetes mellitus. Understanding the biological mechanisms behind these observations may offer new opportunities for diagnosis and therapy.

\section{ACKNOWLEDGEMENTS}

The study was supported by Cancer Research UK; JPN is a Senior Investigator at the National Institutes of Health.

\section{CONFLICT OF INTEREST}

The authors declare no conflict of interest.

\section{AUTHOR CONTRIBUTIONS}

Study concept and design: JK, EC, JPN; acquisition of data: $\mathrm{CH}$, WG, PG, RFL, MML, JM, DP, OS, MWB; analysis and interpretation of data: JK, EC, RJ, MML, JM, OS, MWB, JPN; drafting of the manuscript: JK, EC, JPN; critical revision of the manuscript for important intellectual content: all authors; administrative support: CLR; statistical analysis: RJ, TC; study supervision: JK, JPN.

\section{REFERENCES}

Aggarwal G, Kamada P, Chari ST (2013) Prevalence of diabetes mellitus in pancreatic cancer compared to common cancers. Pancreas 42(2): 198-201.

Aggarwal G, Ramachandran V, Javeed N, Arumugam T, Dutta S, Klee GG, Klee EW, Smyrk TC, Bamlet W, Han JJ, Rumie Vittar NB, de Andrade M, Mukhopadhyay D, Petersen GM, Fernandez-Zapico ME, Logsdon CD, Chari ST (2012) Adrenomedullin is up-regulated in patients with pancreatic cancer and causes insulin resistance in beta cells and mice. Gastroenterology 143(6): 1510-1517 e1.

Ansary-Moghaddam A, Huxley R, Barzi F, Lawes C, Ohkubo T, Fang X, Jee SH, Woodward M. Asia Pacific Cohort Studies C (2006) The effect of modifiable risk factors on pancreatic cancer mortality in populations of the Asia-Pacific region. Cancer Epidemiol Biomarkers Prev 15(12): 2435-2440.

Barone BB, Yeh HC, Snyder CF, Peairs KS, Stein KB, Derr RL, Wolff AC, Brancati FL (2008) Long-term all-cause mortality in cancer patients with preexisting diabetes mellitus: a systematic review and meta-analysis. JAMA 300(23): 2754-2764.

Ben Q, Xu M, Ning X, Liu J, Hong S, Huang W, Zhang H, Li Z (2011) Diabetes mellitus and risk of pancreatic cancer: a meta-analysis of cohort studies. Eur J Cancer 47(13): 1928-1937.

Bosetti C, Lucenteforte E, Silverman DT, Petersen G, Bracci PM, Ji BT, Negri E, Li D, Risch HA, Olson SH, Gallinger S, Miller AB, Bueno-deMesquita HB, Talamini R, Polesel J, Ghadirian P, Baghurst PA, Zatonski W, Fontham E, Bamlet WR, Holly EA, Bertuccio P, Gao YT, Hassan M, Yu H, Kurtz RC, Cotterchio M, Su J, Maisonneuve P, Duell EJ, Boffetta P, La Vecchia C (2012) Cigarette smoking and pancreatic cancer: an analysis from the International Pancreatic Cancer Case-Control Consortium (Panc4). Ann Oncol 23(7): 1880-1888.

Bosetti C, Rosato V, Li D, Silverman D, Petersen GM, Bracci PM, Neale RE, Muscat J, Anderson K, Gallinger S, Olson SH, Miller AB, Bas Bueno-deMesquita H, Scelo G, Janout V, Holcatova I, Lagiou P, Serraino D, Lucenteforte E, Fabianova E, Ghadirian P, Baghurst PA, Zatonski W, Foretova L, Fontham E, Bamlet WR, Holly EA, Negri E, Hassan M, Prizment A, Cotterchio M, Cleary S, Kurtz RC, Maisonneuve P, Trichopoulos D, Polesel J, Duell EJ, Boffetta P, La Vecchia C (2014) Diabetes, antidiabetic medications, and pancreatic cancer risk: an analysis from the International Pancreatic Cancer Case-Control Consortium. Ann Oncol 25(10): 2065-2072.

Calle EE, Murphy TK, Rodriguez C, Thun MJ, Heath CW Jr (1998) Diabetes mellitus and pancreatic cancer mortality in a prospective cohort of United States adults. Cancer Causes Control 9(4): 403-410.

Chari ST, Leibson CL, Rabe KG, Timmons LJ, Ransom J, de Andrade M, Petersen GM (2008) Pancreatic cancer-associated diabetes mellitus: prevalence and temporal association with diagnosis of cancer. Gastroenterology 134(1): 95-101. 
Chu CK, Mazo AE, Goodman M, Egnatashvili V, Sarmiento JM, Staley CA, Galloway JR, Adsay NV, Jacobs S, Kooby DA (2010) Preoperative diabetes mellitus and long-term survival after resection of pancreatic adenocarcinoma. Ann Surg Oncol 17(2): 502-513.

Cox DR (1972) Regression models and life-tables. J R Stat Soc Series B (Methodological) 34(2): 187-220.

Ding XZ, Fehsenfeld DM, Murphy LO, Permert J, Adrian TE (2000) Physiological concentrations of insulin augment pancreatic cancer cell proliferation and glucose utilization by activating MAP kinase, PI3 kinase and enhancing GLUT-1 expression. Pancreas 21(3): 310-320.

Everhart J, Wright D (1995) Diabetes mellitus as a risk factor for pancreatic cancer. A meta-analysis. JAMA 273(20): 1605-1609.

Fisher WE, Boros LG, Schirmer WJ (1996) Insulin promotes pancreatic cancer: evidence for endocrine influence on exocrine pancreatic tumors. J Surg Res 63(1): 310-313.

Gong J, Robbins LA, Lugea A, Waldron RT, Jeon CY, Pandol SJ (2014) Diabetes, pancreatic cancer, and metformin therapy. Front Physiol 5: 426.

Gullo L, Pezzilli R, Morselli-Labate AM. Italian Pancreatic Cancer Study G (1994) Diabetes and the risk of pancreatic cancer. N Engl J Med 331(2): 81-84.

Hart PA, Law RJ, Frank RD, Bamlet WR, Burch PA, Petersen GM, Rabe KG, Chari ST (2014) Impact of diabetes mellitus on clinical outcomes in patients undergoing surgical resection for pancreatic cancer: a retrospective, cohort study. Am J Gastroenterol 109(9): 1484-1492.

Hidalgo M, Cascinu S, Kleeff J, Labianca R, Lohr JM, Neoptolemos J, Real FX, Van Laethem JL, Heinemann V (2015) Addressing the challenges of pancreatic cancer: future directions for improving outcomes. Pancreatology 15(1): 8-18.

Huxley R, Ansary-Moghaddam A, Berrington de Gonzalez A, Barzi F, Woodward M (2005) Type-II diabetes and pancreatic cancer: a metaanalysis of 36 studies. Br J Cancer 92(11): 2076-2083.

Jenkinson C, Elliott V, Evans A, Oldfield L, Jenkins RE, O’Brien DP, Apostolidou S, Gentry-Maharaj A, Fourkala EO, Jacobs I, Menon U, Cox TF, Campbell F, Pereira SP, Tuveson DA, Park PK, Greenhalf W, Sutton RP, Timms JF, Neoptolemos J, Costello E (2015) Decreased serum thrombospondin-1 levels in pancreatic cancer patients up to 24 months prior to clinical diagnosis: association with diabetes mellitus. Clin Cancer Res.

Kaplan EL, Meier P (1958) Nonparametric estimation from incomplete observations. J Am Stat Assoc 53(282): 457-481.

Kikuta K, Masamune A, Hamada S, Takikawa T, Nakano E, Shimosegawa T (2013) Pancreatic stellate cells reduce insulin expression and induce apoptosis in pancreatic beta-cells. Biochem Biophys Res Commun 433(3): 292-297.

Kleeff J, Korc M, Apte M, La Vecchia C, Johnson CD, Biankin AV, Neale RE, Tempero M, Tuveson DA, Hruban RH, Neoptolemos JP (2016) Pancreatic cancer. Nat Rev Dis Primers 2: 16022.

Li D (2012) Diabetes and pancreatic cancer. Mol Carcinog 51(1): 64-74.

Li D, Tang H, Hassan MM, Holly EA, Bracci PM, Silverman DT (2011) Diabetes and risk of pancreatic cancer: a pooled analysis of three large case-control studies. Cancer Causes Control 22(2): 189-197.

Li D, Yeung SC, Hassan MM, Konopleva M, Abbruzzese JL (2009) Antidiabetic therapies affect risk of pancreatic cancer. Gastroenterology 137(2): 482-488.

Litwin J, Dobrowolski S, Orlowska-Kunikowska E, Sledzinski Z (2008) Changes in glucose metabolism after Kausch-Whipple pancreatectomy in pancreatic cancer and chronic pancreatitis patients. Pancreas 36(1): 26-30.

Neoptolemos JP, Dunn JA, Stocken DD, Almond J, Link K, Beger H, Bassi C, Falconi M, Pederzoli P, Dervenis C, Fernandez-Cruz L, Lacaine F, Pap A, Spooner D, Kerr DJ, Friess H, Buchler MW (2001) Adjuvant chemoradiotherapy and chemotherapy in resectable pancreatic cancer: a randomised controlled trial. Lancet 358(9293): 1576-1585.

Neoptolemos JP, Stocken DD, Bassi C, Ghaneh P, Cunningham D, Goldstein D, Padbury R, Moore MJ, Gallinger S, Mariette C, Wente MN, Izbicki JR, Friess H, Lerch MM, Dervenis C, Olah A, Butturini G, Doi R, Lind PA, Smith D, Valle JW, Palmer DH, Buckels JA, Thompson J, McKay CJ,
Rawcliffe CL, Buchler MW. European Study Group for Pancreatic Cancer (2010) Adjuvant chemotherapy with fluorouracil plus folinic acid vs gemcitabine following pancreatic cancer resection: a randomized controlled trial. JAMA 304(10): 1073-1081.

Neoptolemos JP, Stocken DD, Friess H, Bassi C, Dunn JA, Hickey H, Beger H, Fernandez-Cruz L, Dervenis C, Lacaine F, Falconi M, Pederzoli P, Pap A, Spooner D, Kerr DJ, Buchler MW. European Study Group for Pancreatic Cancer (2004) A randomized trial of chemoradiotherapy and chemotherapy after resection of pancreatic cancer. N Engl J Med 350(12): $1200-1210$.

Neoptolemos JP, Stocken DD, Tudur Smith C, Bassi C, Ghaneh P, Owen E, Moore M, Padbury R, Doi R, Smith D, Buchler MW (2009) Adjuvant 5 -fluorouracil and folinic acid $v s$ observation for pancreatic cancer: composite data from the ESPAC-1 and -3(v1) trials. Br J Cancer 100(2): 246-250.

Pannala R, Leirness JB, Bamlet WR, Basu A, Petersen GM, Chari ST (2008) Prevalence and clinical profile of pancreatic cancer-associated diabetes mellitus. Gastroenterology 134(4): 981-987.

Park SM, Lim MK, Shin SA, Yun YH (2006) Impact of prediagnosis smoking, alcohol, obesity, and insulin resistance on survival in male cancer patients: National Health Insurance Corporation Study. J Clin Oncol 24(31): 5017-5024.

Permert J, Ihse I, Jorfeldt L, von Schenck H, Arnquist HJ, Larsson J (1993) Improved glucose metabolism after subtotal pancreatectomy for pancreatic cancer. Br J Surg 80(8): 1047-1050.

Peto R, Peto J (1972) Asymptotically efficient rank invariant test procedures. $J$ R Stat Soc Series A 135(2): 185-207.

R-Development-Core-Team (2011) R: a language and environment for statistical computing. Vol. 1(2.11.1). Vienna, Austria. Available at: http://www.R-project.org/.

Rahib L, Smith BD, Aizenberg R, Rosenzweig AB, Fleshman JM, Matrisian LM (2014) Projecting cancer incidence and deaths to 2030: the unexpected burden of thyroid, liver, and pancreas cancers in the United States. Cancer Res 74(11): 2913-2921.

Schemper M, Smith TL (1996) A note on quantifying follow-up in studies of failure time. Control Clin Trials 17(4): 343-346.

Schoenfeld D (1982) Partial residuals for the proportional hazards regression model. Biometrika 69(1): 239-241.

Siegel RL, Miller KD, Jemal A (2015) Cancer statistics, 2015. CA Cancer J Clin 65(1): 5-29.

Singh S, Singh PP, Singh AG, Murad MH, McWilliams RR, Chari ST (2013) Anti-diabetic medications and risk of pancreatic cancer in patients with diabetes mellitus: a systematic review and meta-analysis. Am J Gastroenterol 108(4): 510-519; quiz 520.

Soranna D, Scotti L, Zambon A, Bosetti C, Grassi G, Catapano A, La Vecchia C, Mancia G, Corrao G (2012) Cancer risk associated with use of metformin and sulfonylurea in type 2 diabetes: a meta-analysis. Oncologist 17(6): 813-822.

Stevens RJ, Roddam AW, Beral V (2007) Pancreatic cancer in type 1 and young-onset diabetes: systematic review and meta-analysis. $\mathrm{Br} J$ Cancer 96(3): 507-509.

van de Poll-Franse LV, Houterman S, Janssen-Heijnen ML, Dercksen MW, Coebergh JW, Haak HR (2007) Less aggressive treatment and worse overall survival in cancer patients with diabetes: a large population based analysis. Int J Cancer 120(9): 1986-1992.

Walter U, Kohlert T, Rahbari NN, Weitz J, Welsch T (2014) Impact of preoperative diabetes on long-term survival after curative resection of pancreatic adenocarcinoma: a systematic review and meta-analysis. Ann Surg Oncol 21(4): 1082-1089.

This work is published under the standard license to publish agreement. After 12 months the work will become freely available and the license terms will switch to a Creative Commons AttributionNonCommercial-Share Alike 4.0 Unported License. 